\title{
Correction to: Persuasion under ambiguity
}

\author{
Jonas Hedlund ${ }^{1} \cdot$ T. Florian Kauffeldt ${ }^{2} \cdot$ Malte Lammert $^{3}$
}

Published online: 17 August 2020

(c) Springer Science+Business Media, LLC, part of Springer Nature 2020

\section{Correction to: Theory and Decision https://doi.org/10.1007/s11238-020-09764-2}

In Proposition 4, lines 3, 4 and 8, 9 were scrambled by mistake during the pagination process of the online published article.

The original article has been corrected accordingly.

We apologize for the error introduced during the production process.

The original article can be found online at https://doi.org/10.1007/s11238-020-09764-2.

* Jonas Hedlund

jonas.hedlund@utdallas.edu

T. Florian Kauffeldt

mail@florian-kauffeldt.com

Malte Lammert

mlammert@ucsd.edu

1 Department of Economics, University of Texas at Dallas, Richardson, USA

2 Department of Economics, Heilbron University, Heilbron, Germany

3 Department of Economics, University of California, San Diego, USA 